\title{
Neutrophil-lymphocyte ratio in patients with major depressive disorder undergoing no pharmacological therapy
}

This article was published in the following Dove Press journal:

Neuropsychiatric Disease and Treatment

27 August 2015

Number of times this article has been viewed

\author{
Süleyman Demir' \\ Abdullah Atli' \\ Mahmut Bulut' \\ Aslıhan Okan İbiloğlu' \\ Mehmet Güneş' \\ Mehmet Cemal Kaya' \\ Özlem Demirpençe ${ }^{2}$ \\ Aytekin Sır' \\ 'Department of Psychiatry, Dicle \\ University, Diyarbakir, ${ }^{2}$ Department \\ of Biochemistry, Cumhuriyet \\ University, Sivas, Turkey
}

Correspondence: Abdullah Atli Department of Psychiatry, Dicle University, Sur, 21280 Diyarbakir, Turkey Tel +90534673 338I

Email abdullahatli@yandex.com
Abstract: Studies attempting to clarify the relationship between major depressive disorder (MDD) and the immune system have been increasing in recent years. It was reported that increased production of the main proinflammatory cytokines, such as interleukin-1, interleukin-6, and tumor necrosis factor-alpha, and that of acute phase reactants may play a role in the etiopathogenesis of depression. Stress and depression were reported to increase leukocyte and neutrophil counts and to decrease lymphocyte count. Biological determinants affecting the diagnosis, therapy, and prognosis of depression are quite limited. Therefore, new etiological models are needed to explain the pathophysiology of depression. In recent years, neutrophillymphocyte ratio (NLR) was determined to be a good indicator of inflammatory status. There is no study in the literature investigating NLR in MDD. This study aims to examine the role of inflammation in the etiology of depression based on the NLR in MDD patients who are undergoing no pharmacological therapy. A total of 41 patients diagnosed with MDD, who received no antidepressant therapy within the past 1 month, were included in the study, which took place between January and March 2015. The control group consisted of 47 healthy subjects with no psychiatric disorders. A sociodemographic information form and a Beck Depression Scale were administered, and the blood was taken for biochemical analysis. Significant differences were identified in the NLR, neutrophil count, lymphocyte percentage, and leukocyte values of the patient group when compared with the control group $(P<0.05)$. Our study is the first in which NLR was investigated in MDD. The findings of the study reveal that NLR tends to be higher in patients with MDD, and a high NLR value supports the view that inflammation is a critical factor in the etiology of MDD.

Keywords: major depressive disorder, neutrophil-lymphocyte ratio, inflammation

\section{Introduction}

The prevalence of major depressive disorder (MDD), one of the most common of all mental complaints, is $\sim 5 \%,{ }^{1,2}$ and many factors are responsible for the MDD etiology. ${ }^{3}$ Studies investigating the possible relationship between MDD and the immune system have been increasing in recent years, and it has been shown that MDD, besides suppressing the immune system, may cause alterations in the inflammatory process. ${ }^{4}$ Furthermore, it has been reported that increased production of the main proinflammatory cytokines such as interleukin-1 (IL-1), interleukin-6 (IL-6), tumor necrosis factor-alpha (TNF-alpha), and that of acute phase reactants may play a role in the etiopathogenesis of depression. ${ }^{5-7}$ Antidepressants have also been shown to decrease and normalize high pretherapeutic serum proinflammatory cytokine levels. ${ }^{6,8}$ In addition, stress and depression may result in an increased number of leukocytes and neutrophils, as well as decreased lymphocytes. ${ }^{4}$ The biological determinants affecting the diagnosis, treatment, 
and prognosis of depression are quite limited, and so new etiological models are needed to explain the pathophysiology of depression. ${ }^{4}$ Recently, the neutrophil-lymphocyte ratio (NLR) has been found to be a good indicator of inflammatory status, ${ }^{9}$ and this ratio has been investigated in a number of diseases, ${ }^{10-12}$ including schizophrenia, a psychiatric disorder, and Alzheimer's disease. These studies have shown that NLR is likely to be higher in both schizophrenia and Alzheimer's patients when compared with healthy subjects. ${ }^{13,14}$ To the best of our knowledge, we have been unable to find a study investigating NLR in MDD patients in the literature.

In the present study, the intention is to examine the role of inflammation in the etiology of depression using NLR in MDD patients who are undergoing no pharmacological therapy, and to define the role of inflammation in the etiology of depression.

\section{Materials and methods Study population}

The study population comprised patients diagnosed with MDB who presented at the Dicle University Psychiatry outpatient clinic between January and March 2015, while the control group comprised healthy volunteers. Only subjects between the ages of 18 and 65 were included in the study.

The patient group involved 41 subjects diagnosed with MDD according to the Diagnostic and Statistical Manual of Mental Disorders, Fifth Edition criteria who had undergone no pharmacological therapy within the previous month, while the control group included 47 healthy subjects with no recorded psychiatric disease. The sociodemographic characteristics of the patients and controls were similar, and so factors such as age, sex, level of education, and body mass index (BMI) were adjusted to prevent any effect on the hemogram variables.

The exclusion criteria were as follows: comorbid psychiatric diseases according to Diagnostic and Statistical Manual of Mental Disorders, Fifth Edition criteria, inflammatory or autoimmune diseases, active infections, a leukocyte value suggesting infection, severe systemic disease, epilepsy, diabetes mellitus, hypertension, cardiac disease, hepatic or renal failure, alcohol or substance addiction, severe head trauma or mental retardation, pregnancy, vitamin or fish oil intake, smoking, obesity $\left(\mathrm{BMI}>30 \mathrm{~kg} / \mathrm{m}^{2}\right.$ ), and concomitant drug use for any reason.

Informed consent was obtained from each participant, and a sociodemographic data form and Beck Depression Scale (BDS) were administered. Blood was taken for biochemical analyses. The study protocol was approved by the institutional local ethics committee.

\section{Data form descriptions}

\section{Sociodemographic information form}

A form developed by the researchers reporting the age, level of education, BMI, smoking habit, and duration of the disease (duration of the last depressive episode).

\section{Beck Depression Scale}

A self-evaluation scale was applied to healthy and psychiatric subjects. The BDS measures signs observed in depression and includes 21 categories of signs, measured with a fourpoint Likert-type scale. Each item is scored between 0 and 3 , which are added together to provide a total score, with the maximum being 63. A high total score is an indicator of depression severity, and a cutoff value of 17 was identified. The BDS was developed by Beck, and validity and reliability studies were performed in our country by Hisli. ${ }^{15,16}$

\section{Blood sampling and hemogram measurements}

After 12 hours of fasting, blood samples were taken from the subjects from the antecubital vein and stored in hemogram tubes (9 am), after which, complete blood parameters were evaluated in the Dicle University Medical Faculty Central Laboratory using an Abbott CELL-DYN Rubby device.

\section{Statistical analysis}

A statistical analysis was carried out using SPSS v15.0 (SPSS Inc., Chicago, IL, USA), and a $\chi^{2}$ test was used to compare categorical variables, frequencies, and ratios. Continuous variables were expressed in mean \pm standard deviation. Normally and abnormally distributed variables were analyzed. A $t$-test was used to compare normally distributed variables between the two groups, while a Mann-Whitney $U$-test was carried out to analyze any abnormally distributed variables. A Pearson correlation analysis was carried out to analyze correlations. A $P$-value of $<0.05$ was considered statistically significant.

\section{Results}

The age, sex, BMI, and level of education were compared for the patient and control groups, and no significant differences were identified in any category. The age, sex, BMI, and level of education data are shown in Table 1.

The complete blood parameters of the patient and control groups were compared statistically, according to which, it was 
Table I Age, sex, BMI, and level of education in the patient and control groups

\begin{tabular}{|c|c|c|c|c|}
\hline & Patient $(n=4 I)$ & Control $(n=47)$ & $\boldsymbol{F}$ & $P$-value \\
\hline Age & $28.4 \pm 9.2$ & $30.0 \pm 9.2$ & 0.3 & 0.401 \\
\hline \multirow[t]{2}{*}{ BMI $\left(\mathrm{kg} / \mathrm{m}^{2}\right)$} & $23.2 \pm 4.1$ & $24.1 \pm 1.4$ & 27.9 & 0.166 \\
\hline & & & $x^{2}$ & $P$-value \\
\hline \multicolumn{5}{|l|}{ Sex } \\
\hline Male & II (26.8\%) & 12 (25.5\%) & 0.019 & 0.890 \\
\hline Female & 30 (73.2\%) & 35 (75.5\%) & & \\
\hline \multicolumn{5}{|l|}{ Education } \\
\hline 0 year & 4 (9.8\%) & $0(0.0 \%)$ & 6.55 & 0.162 \\
\hline 5 years & $9(22.0 \%)$ & 17 (36.2\%) & & \\
\hline 8 years & 9 (22.0\%) & $12(25.5 \%)$ & & \\
\hline II years & $13(31.7 \%)$ & $12(25.5 \%)$ & & \\
\hline$>11$ years & $6(14.6 \%)$ & $6(12.8 \%)$ & & \\
\hline
\end{tabular}

Note: Data presented as mean \pm standard deviation.

Abbreviation: BMI, body mass index.

found that the NLR, neutrophil counts, lymphocyte percentages, and leukocyte values in the patient group differed significantly from those of the control group. The complete blood parameters of the patient and control groups are shown in Table 2.

In the patient group, the age, BMI, and complete blood parameters were compared statistically between the two sexes. The red blood cell (RBC), hematocrit (Htc), and hemoglobin values were determined to be significantly higher in the male patients when compared with the female patients, while the other parameters did not differ significantly between the sexes. The age, BMI, and complete blood parameters of the male and female subjects in the patient group are provided in Table 3.

Correlations among BDS, disease duration, and NLR were identified in the patient group. The BDS did not correlate significantly with either disease duration or NLR ( $\mathrm{r}_{\mathrm{o}}=-0.225, P=0.158 ; \mathrm{r}_{\mathrm{o}}=0.138, P=0.391$, respectively $)$.

\section{Discussion}

The major finding of the present study is that increased NLR values are recorded in depressive patients when compared with healthy subjects. Furthermore, WBC and neutrophil counts are also increased, while lymphocyte percentages are decreased in the patient group when compared with the healthy subjects.

Immune response plays an important role in the etiology of MDD, ${ }^{17}$ and inflammation has been shown to increase in depression. ${ }^{18,19}$ However, there are also some contradictory results. It has been reported that inflammatory change in MDD may be related with the comorbidity of depression and psychiatric disorders, and with such secondary conditions as alcohol use, while it has also been reported that antidepressants and use of other drugs may affect lymphocyte response. ${ }^{20}$ Other factors that may affect inflammatory processes such as comorbid psychiatric disorders, infectious diseases, chronic diseases, alcohol and substance abuse, and the use of antidepressants and other drugs were considered in the exclusion criteria in our study, allowing a more reliable analysis.

Proinflammatory cytokines causing irregularity in the immune system are related with the pathophysiology of depression and tend to be increased in depressive patients. ${ }^{21-23}$ Cytokines such as IL-1, IL-6, and TNF-alpha are known as proinflammatory cytokines and play a major role in inflammatory alterations. In addition, IL-1 is released from such immune system cells as monocytes, lymphocytes, endothelial cells, and microglia. Increased acute phase reactants and neutrophilia may be counted among the functions of TNFalpha. ${ }^{4}$ Also, IL-6 is known to cause a differentiation of B-cells, stimulation of growth in various B-cells, and activation and differentiation in T-cells. ${ }^{24}$ Proinflammatory cytokines have a role in depression pathophysiology, affecting the neurotransmitter metabolism, neuroendocrine functions, and synaptic plasticity. ${ }^{5,25,26}$ Proinflammatory cytokines cause changes in monoamine metabolism. IL-1, IL-6, TNF- $\alpha$ cytokines cause upregulation on serotonin transporter

Table 2 Complete blood parameters in the patient and control groups

\begin{tabular}{lllll}
\hline & Patient $(\mathbf{n}=\mathbf{4 I})$ & Control $(\mathbf{n}=\mathbf{4 7})$ & $\boldsymbol{F}$ & P-value \\
\hline N/L ratio & $2.3 \pm 0.9$ & $2.0 \pm 0.6$ & 7.0 & $0.044^{*}$ \\
Neutrophil $(\%)$ & $60.4 \pm 8.8$ & $58.5 \pm 6.5$ & 3.3 & 0.243 \\
Neutrophil count $\left(\times 10^{3}\right)$ & $4.8 \pm 1.4$ & $4.1 \pm 1.0$ & 7.6 & $0.008^{*}$ \\
Lymphocyte $(\%)$ & $28.7 \pm 7.6$ & $31.8 \pm 6.2$ & 2.5 & $0.039^{*}$ \\
Lymphocyte count $\left(\times 10^{3}\right)$ & $2.2 \pm 0.6$ & $2.2 \pm 0.5$ & 0.5 & 0.644 \\
Leukocyte count $\left(\times 10^{3}\right)$ & $7.8 \pm 1.7$ & $6.9 \pm 1.3$ & 4.3 & $0.008^{*}$ \\
RBC count $\left(10^{6} / \mathrm{mL}\right)$ & $4.9 \pm 0.5$ & $5.0 \pm 0.4$ & 1.3 & 0.317 \\
Htc $(\%)$ & $41.7 \pm 4.1$ & $42.6 \pm 3.9$ & 0.3 & 0.253 \\
Hemoglobin $(\mathrm{g} / \mathrm{dL})$ & $14.0 \pm 1.6$ & $14.4 \pm 1.4$ & 1.3 & 0.119 \\
Plt count $\left(10^{9} / \mathrm{L}\right)$ & $238.5 \pm 57.6$ & $255.6 \pm 46.6$ & 0.1 & 0.128 \\
\hline
\end{tabular}

Notes: Data presented as mean \pm standard deviation. $* P<0.05$ (statistically significant).

Abbreviations: N/L, neutrophil/lymphocyte; Plt, platelet; RBC, red blood cell; Htc, hematocrit. 
Table 3 Age, BMI, and complete blood parameters of the male and female subjects in the patient group

\begin{tabular}{|c|c|c|c|c|}
\hline & Male $(n=I I)$ & Female $(n=30)$ & $\mathbf{Z}$ & $P$-value \\
\hline Age & $29.4 \pm 7.7$ & $28.0 \pm 9.7$ & -0.827 & 0.408 \\
\hline BMI & $24.2 \pm 2.6$ & $24.8 \pm 4.5$ & -1.854 & 0.064 \\
\hline $\mathrm{N} / \mathrm{L}$ ratio & $2.1 \pm 1.1$ & $2.4 \pm 0.9$ & -0.795 & 0.427 \\
\hline Neutrophil (\%) & $56.3 \pm 11.1$ & $62.0 \pm 7.5$ & -1.225 & 0.221 \\
\hline Neutrophil count $\left(\times 10^{3}\right)$ & $4.4 \pm 1.5$ & $5.0 \pm \mathrm{I} .4$ & -1.295 & 0.195 \\
\hline Lymphocyte (\%) & $30.6 \pm 10.0$ & $28.1 \pm 6.5$ & -0.560 & 0.576 \\
\hline Lymphocyte count $\left(\times 10^{3}\right)$ & $2.3 \pm 0.9$ & $2.2 \pm 0.5$ & -0.412 & 0.680 \\
\hline Leukocyte count $\left(\times 10^{3}\right)$ & $7.6 \pm 1.9$ & $7.9 \pm 1.6$ & -0.588 & 0.556 \\
\hline RBC count $\left(10^{6} / \mathrm{mL}\right)$ & $5.5 \pm 0.3$ & $4.7 \pm 0.4$ & -4.260 & $<0.00 I^{*}$ \\
\hline $\mathrm{Htc}(\%)$ & $46.0 \pm 2.2$ & $40.1 \pm 3.5$ & -4.357 & $<0.00 I^{*}$ \\
\hline Hemoglobin (g/dL) & $15.8 \pm 0.9$ & $13.3 \pm 1.3$ & -4.608 & $<0.00 I^{*}$ \\
\hline Plt count $\left(10^{9} / \mathrm{L}\right)$ & $223.6 \pm 29.0$ & $244.0 \pm 64.6$ & -1.340 & 0.180 \\
\hline
\end{tabular}

Notes: Data presented as mean \pm standard deviation. $* P<0.05$ (statistically significant).

Abbreviations: BMI, body mass index; N/L, neutrophil/lymphocyte; Plt, platelet; RBC, red blood cell; Htc, hematocrit.

mRNA and proteins. The amount of serotonin decreases because serotonin neurotransmission increases. Serotonin/ serotonin transporter and inflammation interaction can be a significant point in depression occurrence. ${ }^{25}$ While proinflammatory cytokines changes triptophan metabolism, it decreases serotonin generation from tryptophan, and it causes cinüreic acid and cinolinic acid, which are potential neurotoxic metabolites of triptophan. ${ }^{26}$ These metabolites causing neurotoxicity increase depend on glutamate. On the other hand, neurotropic factors, such as brain-derived neurotrophic factors generation and sinaptic plasticity, decrease. ${ }^{27}$ Proinflammatory cytokines cause desensitization on glucocorticoid receptors, thereby prevent negative feedback mechanism in hypothalamic-pituitary-adrenal axis. This situation leads to the conclusion that hypothalamicpituitary-adrenal axis activities are strongly excited. ${ }^{27}$

Leukocytes, neutrophils, complement, and C-reactive protein are thought to play a role in inflammation, arising in response to depression caused by cytokines. ${ }^{28}$ A study involving mice indicated that circulatory IL-6 and neutrophil values increased as a result of endotoxin exposure. ${ }^{21}$ The activation of T-cells and monocytes by increased IL-1 causes IFN-gamma production, and this is positively related to increases in s and the total leukocyte count. In addition, increased IL-6 releases from activated monocytes in depressive patients seem to be largely in parallel with increased leukocyte-neutrophil ratio and acute phase proteins. ${ }^{4} \mathrm{~A}$ decreased lymphocyte response to mitogen stimulation and disorders in neutrophil activity has been observed in depression. ${ }^{29-31}$ In mice having undergone an olfactory bulbectomy and in various models of learned helplessness, neutrophil phagocytosis was indicated to be a sensory determinant of stress response. ${ }^{32}$ The number, serum concentration and proliferation of lymphocytes, B-cells and T-cells decrease in MDD. Cellular immunity is suppressed, whereas total leukocyte and neutrophil count increase. ${ }^{4,33,34}$ In other studies supporting these findings, lymphocyte proliferation was suppressed, and leukocyte and neutrophil counts were found to be increased in space travelers, while cellular immune functions decreased in subjects undergoing severe stress and those exposed to trauma. ${ }^{35}$ The total T-lymphocyte count has been shown to decrease in depressive patients; however, some T-cell subtypes and activities increased, although the capacity for lymphocyte production did not change significantly when compared with the control group. Neutrophil phagocytes have been shown to decrease in patients diagnosed with endogenous depression when receiving no drugs. ${ }^{36}$ In general, the findings of the present study are consistent with previous studies, indicating increased neutrophil and leukocyte counts and decreased lymphocyte counts. However, our findings showed increased neutrophil counts, with constant percentages and a lower percentage of lymphocytes, and no difference in the lymphocyte count in the patient group when compared with the healthy subjects. These results suggest that evaluating inflammation in relation to neutrophil or lymphocyte separately can be challenging, supporting the need to evaluate NLR in inflammation.

In our study, no significant correlation was determined between BDS and NLR in the patient group, and there are some studies that support our results, indicating no relationship between the immunological response and the severity of the depressive signs in outpatient subjects. ${ }^{37-39}$ However, other authors have reported a relationship between severe depression and immunosuppression. ${ }^{40}$ Among these, Miller et al reported that an increased severity of depression was associated with immunological alterations, while lymphocyte 
response decreased as the severity of depression increased, ${ }^{31}$ although in the present study we were unable to identify a relationship between the severity of depression and NLR. This may be attributed to our study sample comprising only outpatient subjects, although this finding may also indicate that depression, independent of its severity, affects the immune system.

In the patient group, the RBC, Htc, and hemoglobin values were higher in males than in females, although these levels may be expected to be higher in men than in women. The erythrocyte number is normally $5.2 \pm 310^{6} / \mathrm{mL}$ in men and $4.7 \pm 310^{6} / \mathrm{mL}$ in women, while the mean hemoglobin value is $16 \mathrm{~g} / \mathrm{dL}$ in men and $14 \mathrm{~g} / \mathrm{dL}$ in women. Hematocrit values may vary between $40 \%$ and $45 \% .^{41}$ In our study, the RBC, $\mathrm{Htc}$, and hemoglobin values in the male and female patients were within normal ranges, and they were in accordance with the usual differences observed between the two sexes.

This study has some limitations. First, the number of subjects in the groups was low, and depression subgroups, such as atypical or those with melancholic properties, were not evaluated. Other limitations can be listed as follows: the cross-sectional study design, the lack of an analysis of lymphocyte subtypes, and the lack of an analysis of cytokines in combination with NLR.

\section{Conclusion}

This is the first study in which NLR is investigated in MDD and reveals that NLR tends to be higher in patients with MDD. The high value of NLR supports the view that inflammation is a critical factor in the etiology of MDD. Many factors in MDD etiology are the reason, or the result of depression is not certain, and also it is not possible to say NLR level is the reason or result of depression. Nevertheless, according to our obtained data, it is possible to say that inflammation play a role in MDD etiology. On the other hand, more research should be done to determine whether the NLR level is the reason or result of depression. It is apparent that further studies are required to elucidate the exact role of inflammation in the etiology of depression, using NLR alterations following antidepressant therapy.

\section{Disclosure}

The authors report no conflicts of interest in this work.

\section{References}

1. Ferrari AJ, Somerville AJ, Baxter AJ, et al. Global variation in the prevalence and incidence of major depressive disorder: a systematic review of the epidemiological literature. Psychol Med. 2013;43(3):471-481.
2. Baxter AJ, Scott KM, Ferrari AJ, Norman RE, Vos T, Whiteford HA Challenging the myth of an "epidemic" of common mental disorders: trends in the global prevalence of anxiety and depression between 1990 and 2010. Depress Anxiety. 2014;31(6):506-516.

3. Myint AM, Kim YK. Cytokine-serotonin interaction through IDO: a neurodegeneration hypothesis of depression. Med Hypotheses. 2003;61(5-6): 519-525.

4. Tuglu C, Kara SH. Depression, cytokines and immune system. Bull Clin Psychopharmacol. 2003;13:142-150.

5. Raison CL, Capuron L, Miller AH. Cytokines sing the blues: inflammation and the pathogenesis of depression. Trends Immunol. 2006;27: 24-31.

6. Janssen DG, Caniato RN, Verster JC, Baune BT. A psychoneuro immunological review on cytokines involved in antidepressant treatment response. Hum Psychopharmacol. 2010;25:201-215.

7. Krishnadas R, Cavanagh J. Depression: an inflammatory illness? J Neurol Neurosurg Psychiatry. 2012;83:495-502.

8. Hannestad J, DellaGioia N, Bloch M. The effect of antidepressant medication treatment on serum levels of inflammatory cytokines: a meta-analysis. Neuropsychopharmacology. 2011;36:2452-2459.

9. Gibson PH, Cuthbertson BH, Croal BL, et al. Usefulness of neutrophil/ lymphocyte ratio as predictor of new-onset atrial fibrillation after coronary artery bypass grafting. Am J Cardiol. 2010;105:186-191.

10. Azab B, Jaglall N, Atallah JP, et al. Neutrophil-lymphocyte ratio as a predictor of adverse outcomes of acute pancreatitis. Pancreatology. 2011;11: 445-452.

11. Gwak MS, Choi SJ, Kim JA, et al. Effects of gender on white blood cell populations and neutrophil-lymphocyte ratio following gastrectomy in patients with stomach cancer. J Korean Med Sci. 2007;22:104-108.

12. Kaya MG, Akpek M, Lam YY, et al. Prognostic value of neutrophil/ lymphocyte ratio in patients with ST-elevated myocardial infarction undergoing primary coronary intervention: a prospective, multicenter study. Int J Cardiol. 2013;168(2):1154-1159.

13. Semiz M, Yildirim O, Canan F, et al. Elevated neutrophil/lymphocyte ratio in patients with schizophrenia. Psychiatr Danub. 2014;26(3):220-225.

14. Kuyumcu ME, Yesil Y, Oztürk ZA, et al. The evaluation of neutrophillymphocyte ratio in Alzheimer's disease. Dement Geriatr Cogn Disord. 2012;34:69-74.

15. Beck AT. An inventory for measuring depression. Arch Gen Psychiatry. 1961;4:561-571.

16. Hisli N. Beck depresyon envanterinin üniversite öğrencileri için geçerliği, güvenirliği [Reliability and validity of the Beck Depression Inventory for university students]. Psikoloji Dergisi. 1989;7:13. Turkish.

17. Sadock BJ, Sadock VA. Kaplan and Sadock's Synopsis of Psychiatry. 9th ed. Lippincott, Williams and Wilkins, (Çev. ed.: Bozkurt A). Güneş Tip Kitabevleri. Ankara. 3:128-133;15:536-539.

18. Leonard BE. The immune system, depression and the action of antidepressants. Prog Neuropsychopharmacol Biol Psychiatry. 2001;25: 767-780.

19. Raison CL, Miller AH. Is depression an inflammatory disorder? Curr Psychiatry Rep. 2011;13:467-475.

20. Stein M, Miller AH, Trestman RL. Depression, the immune system, and healthy and illness. Arch Gen Psychiatry. 1991;48:171-177.

21. Fonseka TM, Mclntyre RS, Soczynska JK, Kennedy SH. Novel investigational drugs targeting IL-6 signaling for the treatment of depression. Expert Opin Investig Drugs. 2015;24(4):459-475.

22. Dowlati Y, Herrmann N, Swardfager W, et al. A metaanalysis of cytokines in major depression. Biol Psychiatry. 2010;67:446-457.

23. Howren MB,LamkinDM, Suls J. Associations of depression withC-reactive protein, IL-1, and IL-6: a meta-analysis. Psychosom Med. 2009;71: 171-186.

24. Akira S, Taga T, Kishimoto T. IL-6 biology and medicine. Adv Immunol. 1993;54:1-78

25. Maes M, Ringel K, Kubera M, Berk M, Rybakowski J. Increased autoimmune activity against 5-HT: a key component of depression that is associated with inflammation and activation of cell-mediated immunity, and with severity and staging of depression. J Affect Disord. 2012;136:386-392. 
26. Raedler TJ. Inflammatory mechanisms in major depressive disorder. Curr Opin Psychiatry. 2011;24:519-525.

27. Miller AH, Maletic V, Raison CL. Inflammation and its discontents: the role of cytokines in the pathophysiology of major depression. Biol Psychiatry. 2009;65:732-741.

28. Kiecolt-Glaser JK, Marucha PT, Malarkey WB, Mercado AM, Glaser R. Slowing of wound healing by psychological stress. Lancet. 1995;346: 1194-1196.

29. Sertöz ÖÖ, Mete HE. Bedensel Hastalıklarda Depresyon [Depression in somatic illness]. Klinik Psikiyatri. 2004;(Suppl)2:63-69. Turkish.

30. Rothermundt M, Arolt V, Fenker J, Gutbrodt H, Peters M, Kirchner H. Different immune patterns in melancholic and non-melancholic major depression. Psychiatry Clin Neurosci. 2001;251:90-97.

31. Miller GE, Cohen S, Herbert TB. Pathways linking major depression and immunity in ambulatory female patients. Psychosom Med. 1999;61: $850-860$.

32. Song C, Leonard BE. The effect of olfactory bulbectomy in the rat, alone or in combination with antidepressants and endogenous factors, on immune function. Hum Psychopharmacol. 1995;10:7-18.

33. Seidel A, Arolt V, Hunstiger M, Rink L, Behnisch A, Kirchner H. Cytokine production and serum proteins in depression. Scand J Immunol. 1995;41: 534-538.

34. Zorrilla EP, Luborsky L, McKay JR, et al. The relationship of depression and stressors to immunological assays: a metaanalytic review. Brain Behav Immun. 2001;15:199-226.
35. Maes M. Evidence for an immune response in major depression: a review and hypothesis. Prog Neuropsychopharmacol Biol Psychiatry. 1995;19: 11-13.

36. Mc Adams C, Leonard BE. Neutrophil and monocyte phagocytosis in depressed patients. Prog Neuropsychopharmacol Biol Psychiatry. 1993; 17:971-984.

37. Andreoli A, Keller SE, Rabaeus M, Marin P, Bartlett JA, Taban C. Depression and immunity: age, severity, and clinical course. Brain Behav Immun. 1993; 7:279-292.

38. Schleifer SJ, Keller SE, Bartlett JA, Eckholdt HM, Delaney BR. Immunity in young adults with major depressive disorder. Am J Psychiatry. 1996;153:477-482.

39. Ravindran AV, Griffiths J, Merali Z, Anisman H. Circulating lymphocyte subsets in major depression and dysthymia with typical or atypical features. Psychosom Med. 1998;60:283-289.

40. Mittwoch-Jaffe T, Shalit F, Srendi B, Yehuda S. Modification of cytokine secretion following mild emotional stimuli. Neuroreport. 1995;6: 789-792.

41. Guyton AC, Hall JE. Textbook of Medical Physiology. 9th ed. İstanbul: W.B. Saunders Company; 1996:425-426. [Çev. ed.: Çavuşoğlu H, Türkçe, Nobel Tıp Kitap Evi].

\section{Publish your work in this journal}

Neuropsychiatric Disease and Treatment is an international, peerreviewed journal of clinical therapeutics and pharmacology focusing on concise rapid reporting of clinical or pre-clinical studies on a range of neuropsychiatric and neurological disorders. This journal is indexed on PubMed Central, the 'PsycINFO' database and CAS, and is the official journal of The International Neuropsychiatric Association (INA). The manuscript management system is completely online and includes a very quick and fair peer-review system, which is all easy to use. Visit http://www.dovepress.com/testimonials.php to read real quotes from published authors. 